\title{
Single step sol-gel made silver chloride on Titania xerogels to inhibit $E$. coli bacteria growth: effect of preparation and chloride ion on bactericidal activity
}

\author{
Mert Tuncer • Erol Seker
}

Received: 5 April 2011/Accepted: 17 May 2011/Published online: 26 May 2011

(C) Springer Science+Business Media, LLC 2011

\begin{abstract}
We report the antibacterial efficacies of silver and/or silver chloride containing titania xerogels synthesized with modified single step sol-gel methods against Escherichia coli bacteria. As the silver loading in $\mathrm{TiO}_{2}$ increases, the amount of the xerogel required to inhibit the growth of the bacteria decreases and also we found that pure $\mathrm{TiO}_{2}$ was not bactericidal. Among modified single step sol-gel methods used in this study, the additional $\mathrm{HCl}$ treatment sol-gel route III was very effective to obtain only $\mathrm{AgCl}$ crystallites in $\mathrm{TiO}_{2}$. Based on viable cell count method, $0.125 \mathrm{~g} / \mathrm{L}$ of $29 \% \mathrm{Ag} / \mathrm{TiO}_{2}$ (made with $\mathrm{HNO}_{3}$ solgel route I) was enough to inhibit the growth of $E$. coli whereas $0.6 \mathrm{~g} / \mathrm{L}$ of $29 \% \mathrm{Ag} / \mathrm{TiO}_{2}$ (made with the additional $\mathrm{HCl}$ treatment sol-gel route III) was required. However, antibacterial activity of $29 \% \mathrm{Ag} / \mathrm{TiO}_{2}$ (made with $\mathrm{HNO}_{3}$ sol-gel route I) after 6 usages was the same as $29 \% \mathrm{Ag} / \mathrm{TiO}_{2}$ (made with the additional $\mathrm{HCl}$ treatment sol-gel route III).
\end{abstract}

Keywords Sol-gel $\cdot$ Xerogels $\cdot$ Silver $\cdot$ Silver chloride Titania $\cdot$ E. coli

\section{Introduction}

Some microorganisms, such as E. coli bacteria, may adversely affect our health through many infectious routes; for example, ingestion and inhalation. Bacteria can be eliminated from contaminated areas using chemical and mechanical means. Cleaning with chemicals which are toxic and corrosive is time consuming and labor intensive

M. Tuncer · E. Seker $(\square)$

Chemical Engineering Department, Izmir Institute

of Technology, Urla, Izmir 35430, Turkey

e-mail: erolseker@iyte.edu.tr procedure. Instead, the growth of bacteria can be inhibited using materials containing biocidal additives, such as silver, copper and zinc [1, 2]. Among these additives, silver salts and compounds, such as silver nitrate and silver sulfadiazine; have been known as effective antibacterial agents in medicine for a long time. For example, they were sold as cures for treating local infections as early as 1902 and also they have been used in the treatment of burns in clinics since 1965 [3-5]. In addition to these medical and clinical usages, silver compounds have been recently used as biocidal additives in many practices ranging from the sterilization of water, to the antimicrobial food packaging, to preservative usages in cosmetics, to the long lasting sanitization of public facilities, such as public telephones and toilet seats [6, 7].

Antibacterial materials are known to be biocidal in inhibiting the growth of bacteria when they are in the form of soluble ions and/or nano-particles. For example, Gupta et al. reported that water soluble ionic Ag-halide complexes, such as $\mathrm{AgCl}_{2}{ }^{-}$, in addition to water soluble $\mathrm{Ag}^{+}$ ion could be very active in reducing bacteria population on agar media [8]. Metal and metal oxide nanoparticles, such as silver and magnesium oxide, were also found to be effective against bacteria [9-11]. On the other hand, nanoparticles in liquid systems are known to suffer from the aggregation due to the presence of bacteria, hence leading to decrease in their biocidal activities [9].

The slow release of the soluble $\mathrm{Ag}^{+}$ions and/or complexes seems to be a better approach to achieve long lasting protection against bacteria. This can be accomplished through the incorporation and stabilization of ionic silver species in inorganic or organic carriers, such as fibers, zeolite and polymers [12-14]. Rivera-Garza et al. [12] prepared natural zeolite supported silver using ionexchange method and found out that silver loaded natural 
zeolites were effective in destroying $E$. coli and $S$. faecalis bacteria in the solution and the efficacy of these zeolites depended on the silver amount and the contact time. Estevao et al. [15] found that the silver impregnated waste oil refinery catalysts which were incorporated in the polyurethane had biocidal activity against $S$. aureus, E. coli, C. humicolus and C. tropicalis. Besides, Jeon et al. [16] reported that silver doped silica thin films prepared using tetraethyl ortosilicate and silver nitrate in the sol-gel method were very active bactericides against $E$. coli and S. aureus. Similarly, Trapalis et al. [17] showed that the sol-gel synthesized copper doped silica thin films coated on the microscope glass plates were very active in destroying $E$. coli bacteria. In the last few years, several studies on silver containing titania materials were reported. Thiel et al. studied the antibacterial properties of silver-doped titania nanoparticles by the sol-gel technique [18]. Following the study of Thiel et al., several other studies focused on antibacterial properties of silver containing $\mathrm{TiO}_{2}$ composites were published [19-22]. However, to the best of our knowledge, there is no study on understanding the effect of crystallite phase and counter ion effect on the bactericidal activities and also on the long term usage of the titania supported silver.

In this manuscript, we report the effect of preparation conditions and silver amount on the bactericidal activity and silver release of titania supported silver xerogels made through the three modified sol-gel routes.

\section{Experimental section}

\subsection{Synthesis of silver or silver chloride containing titania xerogels}

We modified the sol-gel method given in ref. [23] to synthesize pure titania, silver and/or silver chloride containing titania xerogels in a single-step sol-gel approach. The procedures used in this study are summarized in Fig. 1. Silver nitrate (99\% purity, from Aldrich Inc.) was used as silver precursor. For silver containing titania xerogels, 1.2 wt.\%, 12 wt. $\%$ and 29 wt.\% Ag loadings were used.

\subsection{1 $\mathrm{HNO}_{3}$ sol-gel route I}

For the synthesis of $\mathrm{Ag} / \mathrm{TiO}_{2}$ xerogels, tetrabutyl-orthotitanate (TBOT) (99\% purity, from Aldrich Inc.), nitric acid (65\% purity, from Aldrich Inc.) and ethanol (99\% purity, from Aldrich Inc.) were used without further purification. The molar ratio of $\left[\mathrm{HNO}_{3}\right] /[\mathrm{Ti}]=0.087,\left[\mathrm{H}_{2} \mathrm{O}\right] /[\mathrm{Ti}]=4$ and $[$ Ethanol $] /[\mathrm{Ti}]=27$ were used in the preparation. After mixing TBOT and ethanol at room temperature, the mixture of $\mathrm{HNO}_{3}$ and water was added to obtain the sol.

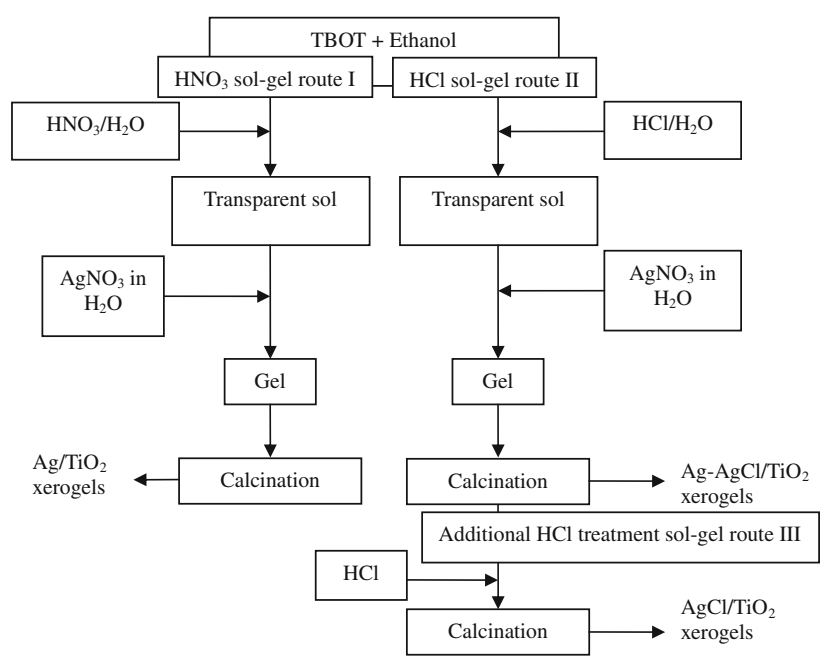

Fig. 1 The sol-gel procedures used in this study

Then, the necessary amount of $\mathrm{AgNO}_{3}$ in water was added to the sol to obtain the gel. Finally, all the gels were calcined at $400{ }^{\circ} \mathrm{C}$ for $3 \mathrm{~h}$. The xerogels obtained in this way is designated as the silver loading preceding $\mathrm{Ag} / \mathrm{TiO}_{2}$ notation throughout the manuscript. For instance, for 1.2 wt.\% Ag loading, it is $1.2 \% \mathrm{Ag} / \mathrm{TiO}_{2}$.

\subsection{2 $\mathrm{HCl}$ sol-gel route II}

Hydrochloric acid $(\mathrm{HCl})$ was used in the synthesis of Ag-AgCl/TiO 2 xerogels. Tetrabutyl-orthotitanate (TBOT) and ethanol were mixed at room temperature. After that, hydrochloric acid was diluted with water, and was added to tetrabutyl-orthotitanate-ethanol solution. In the synthesis, molar ratios of $[\mathrm{HCl}] /[\mathrm{Ti}]=0.25,\left[\mathrm{H}_{2} \mathrm{O}\right] /[\mathrm{Ti}]=4$ and $[$ Ethanol] $/[\mathrm{Ti}]=27$ were used. $\mathrm{HCl}$ acid was first diluted with half of the total amount of water and then was added to tetrabutyl-orthotitanate and ethanol mixture. The required amount of silver nitrate was dissolved in the second half of the total amount of water and slowly added to partially hydrolyzed tetrabutyl-orthotitanate solution. The gelation occurred without formation of precipitates in $1 \mathrm{~h}$. Once the gels were obtained, they were calcined at $400{ }^{\circ} \mathrm{C}$ for $3 \mathrm{~h}$. Similar to route I, the xerogels obtained in this route II is designated as the silver loading preceding $\mathrm{Ag}-\mathrm{AgCl} / \mathrm{TiO}_{2}$ notation throughout the manuscript. For instance, for $1.2 \mathrm{wt} . \% \mathrm{Ag}$ loading, it is $1.2 \% \mathrm{Ag}-\mathrm{AgCl} /$ $\mathrm{TiO}_{2}$.

\subsubsection{Additional HCl treatment sol-gel route III}

In order to form only $\mathrm{AgCl}$ nanocrystals in $\mathrm{TiO}_{2}, \mathrm{Ag}-\mathrm{AgCl} /$ $\mathrm{TiO}_{2}$ xerogels were further treated with $\mathrm{HCl}$ acid using incipient wetness impregnation. Finally, $\mathrm{HCl}$ treated xerogels were calcined at $200{ }^{\circ} \mathrm{C}$ for $2 \mathrm{~h}$. The xerogels obtained 
in this route III is designated as the silver loading preceding $\mathrm{AgCl} / \mathrm{TiO}_{2}$ notation throughout the manuscript. For instance, for $1.2 \mathrm{wt} . \% \mathrm{Ag}$ loading, it is $1.2 \% \mathrm{AgCl} / \mathrm{TiO}_{2}$.

\subsection{Materials characterizations}

Crystallite size and phases present in the materials were determined by X-ray diffraction (Philips X'pert Pro XRD, operated at $40 \mathrm{kV}$ and $45 \mathrm{~mA}$ ). Average crystallite sizes of silver and silver chloride were calculated from the broadening of X-ray diffraction peak and the Scherrer equation.

\subsection{Bactericidal activity measurements}

The antibacterial efficacies of the titania supported silver xerogels were evaluated by using two methods: (1) disk diffusion and (2) viable cell count. In the disk diffusion method, the medium was prepared by using Mueller-Hinton broth (from Mercks Co.) and agar agar (from Mercks Co.). Bacteria cells were grown in the growth medium at $37{ }^{\circ} \mathrm{C}$ overnight. E. coli colony was dissolved in $1 \mathrm{~mL}$ of distilled water; the turbidity was adjusted to McFarland no. $0.5\left(10^{8}\right.$ $\mathrm{CFU} / \mathrm{mL}$ ). After soaking a sterile cotton swab in the bacterial suspension, the swab was streaked in at least 2 directions over the surface of the Mueller-Hinton agar to obtain uniform growth. Plates were divided into 4 parts. $8 \mathrm{~mm}$ in diameters of pellets (each of them were about $0.1 \mathrm{~g}$ ) were prepared using a hydraulic press at ambient temperature and placed in each division on the plates. Then, the plates were incubated at $37^{\circ} \mathrm{C}$. After 1 day of incubation, the zone diameter was measured. The zones were measured with digital caliper at 4 different symmetric points around the antibacterial zone in order to minimize the measurement errors.

In viable cell count method, $E$. coli bacterial cultures were first grown on nutrient agar plates at $37{ }^{\circ} \mathrm{C}$ for overnight. Sufficient amount of $E$. coli colony was dissolved in $0.9 \% \mathrm{NaCl}$-water to adjust the turbidity to McFarland no. $0.5\left(10^{8} \mathrm{CFU} / \mathrm{mL}\right)$. Sterile tissue culture plates ( 24 well with $2 \mathrm{~mL}$ volumes) were obtained from Becton Dickinson Labware Company. $0.1 \mathrm{~mL}$ of bacteria suspension and $1.9 \mathrm{~mL}$ of liquid Mueller-Hinton broth was added into the well containing different amount of xerogels. They were incubated at $37^{\circ} \mathrm{C}$ for $24 \mathrm{~h}$. After that, $0.1 \mathrm{~mL}$ of liquid sample was added on nutrient agar plates and spread out over the plates. Plates were incubated at $37{ }^{\circ} \mathrm{C}$ for $24 \mathrm{~h}$. Finally, cells grown were counted on the plates.

\subsection{Determination of silver dissolution from selected xerogels}

$0.1 \mathrm{~g}$ of each powder was put into the falcon tubes containing $25 \mathrm{~mL}$ of deionized water. They were placed in a shaking incubator to mix the content while keeping the temperature constant at $30^{\circ} \mathrm{C}$ for $24 \mathrm{~h}$. Then, they were centrifuged and filtered with a filter paper. As the solid content was removed, the liquid samples were acidified with about $2 \% \mathrm{HNO}_{3}$. The samples were tested at Agilent 7500ce Series inductively coupled plasma quadruple mass spectrometer (ICP-MS) (Tokyo, Japan) without further dilution.

\section{Results}

Figure 2 shows the results of the disk diffusion tests for all the xerogels made with $\mathrm{HCl}$ sol-gel route II as a function of silver loading. The error bars given in the figure represent 95\% confidence interval in the measurement of the zone diameter. As seen in the figure, three duplicate for each silver loading indicates that the results are reproducible. In fact, the antibacterial activity of the xerogels increased with the silver loading. For example, $\sim 25 \%$ increase in the zone diameter was observed when Ag loading was changed from 1.2 to $12 \%$ but further increase of Ag loading to $29 \%$ resulted in only $\sim 6 \%$ expansion in the zone diameter. In contrast, pure titania (i.e. without silver) made with the same sol-gel routes using both $\mathrm{HNO}_{3}$ and $\mathrm{HCl}$ was not bactericidal against E. coli (data not shown). The reason why 29 wt.\% of high silver loading was used is because final percentage of the antibacterial agent in a host matrix, such as a polymer, is generally desired to be $\sim 1 \mathrm{wt} . \%$. Based on the disk diffusion results and the $1 \mathrm{wt} . \%$ requirement, we focused our attention on $29 \mathrm{wt} . \% \mathrm{Ag}$ containing $\mathrm{TiO}_{2}$ xerogel.

Figure 3 shows the XRD patterns of $29 \% \mathrm{Ag} / \mathrm{TiO}_{2}$ xerogels prepared with the three preparation routes mentioned in the experimental section. It is clearly seen from the figure that silver is in metallic form in $\mathrm{Ag} / \mathrm{TiO}_{2}$ xerogel synthesized with the $\mathrm{HNO}_{3}$ sol-gel route I whereas the one

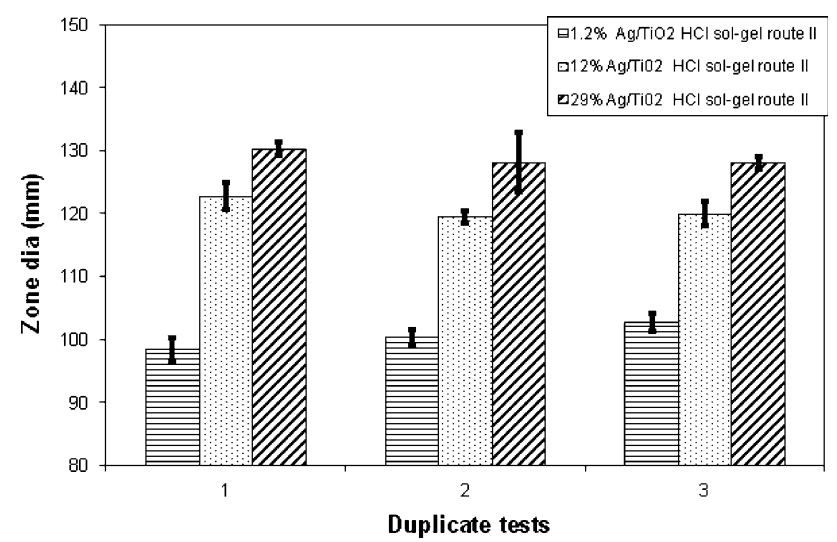

Fig. 2 Disk diffusion method: Ag loading effect on the bactericidal activity of the xerogels made with $\mathrm{HCl}$ sol-gel route II 


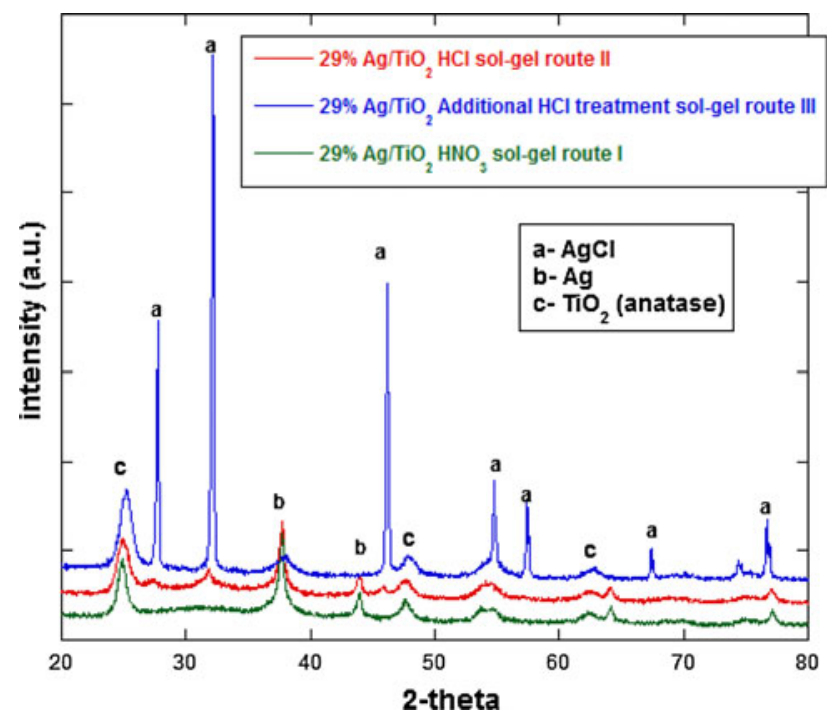

Fig. 3 XRD patterns of $29 \% \mathrm{Ag} / \mathrm{TiO}_{2}$ xerogels prepared with the three preparation routes

synthesized through $\mathrm{HCl}$ sol-gel route II (i.e. $\mathrm{Ag}-\mathrm{AgCl} /$ $\mathrm{TiO}_{2}$ ) contains both $\mathrm{Ag}$ and $\mathrm{AgCl}$ crystallite phases. Interestingly, we found that additional $\mathrm{HCl}$ treatment solgel route III ensured the conversion of metallic Ag crystallites into $\mathrm{AgCl}$ in $\mathrm{TiO}_{2}$. In fact, our observations are in parallel with the studies given in the literature. For instance, $\mathrm{Li}$ et al. [24] found that $\mathrm{Ag}$ nano-crystallites were highly reactive toward $\mathrm{HCl}$ to form $\mathrm{AgCl}$ although it is well known that bulk silver does not react with $\mathrm{HCl}$ acid. In addition, we found from EDX surface elemental analysis of two xerogels, $29 \% \mathrm{Ag} / \mathrm{TiO}_{2}$ and $29 \% \mathrm{Ag}-\mathrm{AgCl} / \mathrm{TiO}_{2}$, that the silver was fairly uniformly dispersed on $\mathrm{TiO}_{2}$ even though silver loading was 29 wt.\% (data not shown). Besides, from the line broadening of XRD peaks and Scherrer equation, we calculated the average crystallite size of $\mathrm{Ag}$ and $\mathrm{AgCl}$ in the unused (i.e. fresh) xerogels made with three sol-gel routes for $29 \%$ silver loading. As seen in Table 1, the additional $\mathrm{HCl}$ treatment sol-gel route III resulted in the formation of the largest $\mathrm{AgCl}$ crystallites ( $\sim 65 \mathrm{~nm}$ in diameter) and with the $\mathrm{HCl}$ sol-gel route II, $\mathrm{Ag}$ and $\mathrm{AgCl}$ crystallites of $\sim 16$ and $\sim 12 \mathrm{~nm}$ in diameter, respectively, were present. In contrast, $\mathrm{HNO}_{3}$ sol-gel route I produced only metallic Ag with $\sim 16 \mathrm{~nm}$ of average crystallite size.

Table 1 Average crystallite sizes of $29 \% \quad \mathrm{Ag}-\mathrm{TiO}_{2}$ pellets before used in antibacterial tests

\begin{tabular}{lcc}
\hline & $\mathrm{Ag}(\mathrm{nm})$ & $\mathrm{AgCl}(\mathrm{nm})$ \\
\hline $29 \% \mathrm{Ag}-\mathrm{AgCl} / \mathrm{TiO}_{2}$ & 15.6 & 11.6 \\
$29 \% \mathrm{Ag} / \mathrm{TiO}_{2}$ & 16.4 & - \\
$29 \% \mathrm{AgCl} / \mathrm{TiO}_{2}$ & - & 64.6 \\
\hline
\end{tabular}

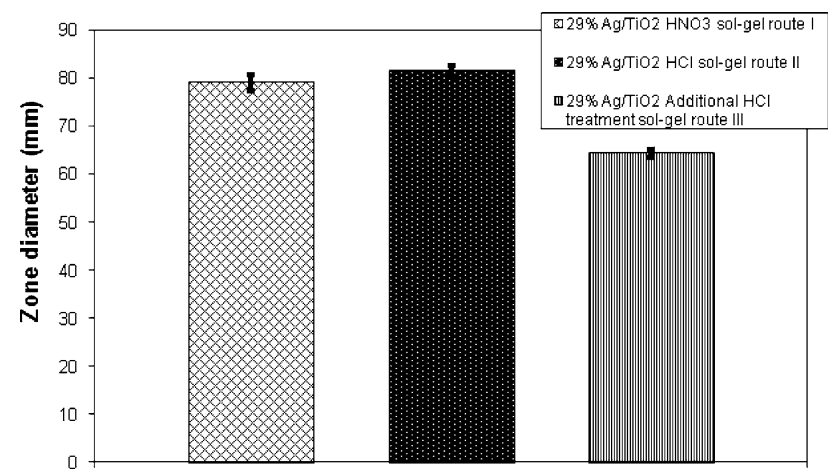

Fig. 4 Bactericidal activities of all the 29 wt.\% $\mathrm{Ag} / \mathrm{TiO}_{2}$ xerogels made with three sol-gel routes

Table 2 Minimum amounts required for the inhibition of E. coli growth for silver titania xerogels

\begin{tabular}{|c|c|}
\hline & $\begin{array}{l}\text { Minimum amount required to } \\
\text { inhibit bacteria growth }(\mathrm{g} / \mathrm{L})\end{array}$ \\
\hline $\begin{array}{l}1.2 \% \mathrm{AgCl} / \mathrm{TiO}_{2} \\
\text { (made with the additional } \mathrm{HCl} \\
\text { treatment sol-gel route III) }\end{array}$ & 5.6 \\
\hline $\begin{array}{l}12 \% \mathrm{AgCl} / \mathrm{TiO}_{2} \\
\text { (made with the additional } \mathrm{HCl} \\
\text { treatment sol-gel route III) }\end{array}$ & 2.5 \\
\hline $\begin{array}{l}29 \% \mathrm{AgCl} / \mathrm{TiO}_{2} \\
\text { (made with the additional } \mathrm{HCl} \\
\text { treatment sol-gel route III) }\end{array}$ & 0.6 \\
\hline $\begin{array}{l}29 \% \mathrm{Ag} / \mathrm{TiO}_{2} \\
\quad \text { (made with } \mathrm{HNO}_{3} \text { sol-gel route I) }\end{array}$ & 0.125 \\
\hline
\end{tabular}

Figure 4 shows the antibacterial activities of all the 29 wt. $\% \mathrm{Ag} / \mathrm{TiO}_{2}$ xerogels made with three sol-gel routes. We found that there was no significant difference in the bactericidal activities of the xerogels made with $\mathrm{HNO}_{3}$ sol-gel route I and $\mathrm{HCl}$ sol-gel route II within our measurement errors. However, the xerogel made with additional $\mathrm{HCl}$ treatment sol-gel route III was $\sim 25 \%$ less bactericidal than the others. In order to better understand bactericidal activities of $29 \mathrm{wt} . \% \mathrm{Ag} / \mathrm{TiO}_{2}$ xerogels, $\mathrm{Ag}$ ion released to deionized water from the xerogels made with $\mathrm{HNO}_{3}$ sol-gel route I and also the additional $\mathrm{HCl}$ treatment sol-gel route III was studied using ICP analysis. We found that silver concentration in water that was released from the xerogel made with additional $\mathrm{HCl}$ treatment sol-gel route III was $117 \mathrm{ppb}$ whereas for the xerogel made with $\mathrm{HNO}_{3}$ sol-gel route I, it was $680 \mathrm{ppb}$.

Based on the viable cell counting method, the minimum amounts of the xerogels required to inhibit the growth of bacteria are given in Table 2. It is seen that as the silver loading increases, minimum amount required for the xerogels made with the additional $\mathrm{HCl}$ treatment sol-gel 
route III decreases from 5.6 to $0.6 \mathrm{~g} / \mathrm{L}$. In contrast, $29 \% \mathrm{Ag} /$ $\mathrm{TiO}_{2}$ made with $\mathrm{HNO}_{3}$ sol-gel route I showed the lowest minimum amount required to inhibit the bacteria growth, $0.125 \mathrm{~g} / \mathrm{L}$. In other words, the amount of the xerogel necessary to inhibit the growth of bacteria is very low for $29 \% \mathrm{Ag} / \mathrm{TiO}_{2}$ made with $\mathrm{HNO}_{3}$ sol-gel route I.

\section{Discussion}

\subsection{Chloride ion effect on antibacterial activity}

Antibacterial activity reported in literature was mostly correlated with the silver crystallite size (i.e., the smaller the silver crystallite size, the higher the antibacterial activity) without measuring the dissolution rate of silver $[18,21]$. Also, the effect of chloride ion present in the nutrient was ignored in the studies reported in literature. Our results are not in parallel with this trend reported in the literature since the different preparation methods was used in our study and the chloride ion effect was considered. We found that the presence of chloride ion either in medium or in the xerogels significantly affects the dissolution of silver; hence, the antibacterial activity. For instance, one should notice that the bulk silver does not dissolve in water unless there is some counter ions, such as chloride, present in water. However, it is known that nano-silver is soluble in water $[25,26]$. Therefore, it is plausible that silver was released to water from xerogel made with $\mathrm{HNO}_{3}$ sol-gel route I since the crystallite size of the silver in this xerogel was $\sim 16 \mathrm{~nm}$. Our ICP analyses also support this finding because the dissolution of silver was very high for this xerogel; hence, leading to a high concentration of silver in the medium. However, for the xerogel made with the additional $\mathrm{HCl}$ treatment sol-gel route III (i.e. contains only $\mathrm{AgCl}$ crystalline phase), the amount of xerogel necessary to inhibit the bacterial growth is high because of the low dissolution of silver chloride; hence, low silver concentration in the medium. It should be noted that the initial bacteria concentration in our study was higher than the other studies in the literature. It is hard to compare the results of antibacterial tests reported by different research groups, since the experimental conditions, such as initial bacteria concentration, active material composition, test procedures and types vary among studies and laboratories around the world [18, 19, 21].

The small zone diameter formation found in disk diffusion tests for low silver loading, such as $1.2 \% \mathrm{Ag}$, seems to indicate the slow release of silver ions; hence, resulting in low amount of silver during the incubation time. However, this would be correct if there were no interaction between the diffusing silver cation and the reactive anions, such as chloride ion, in the MH agar medium.

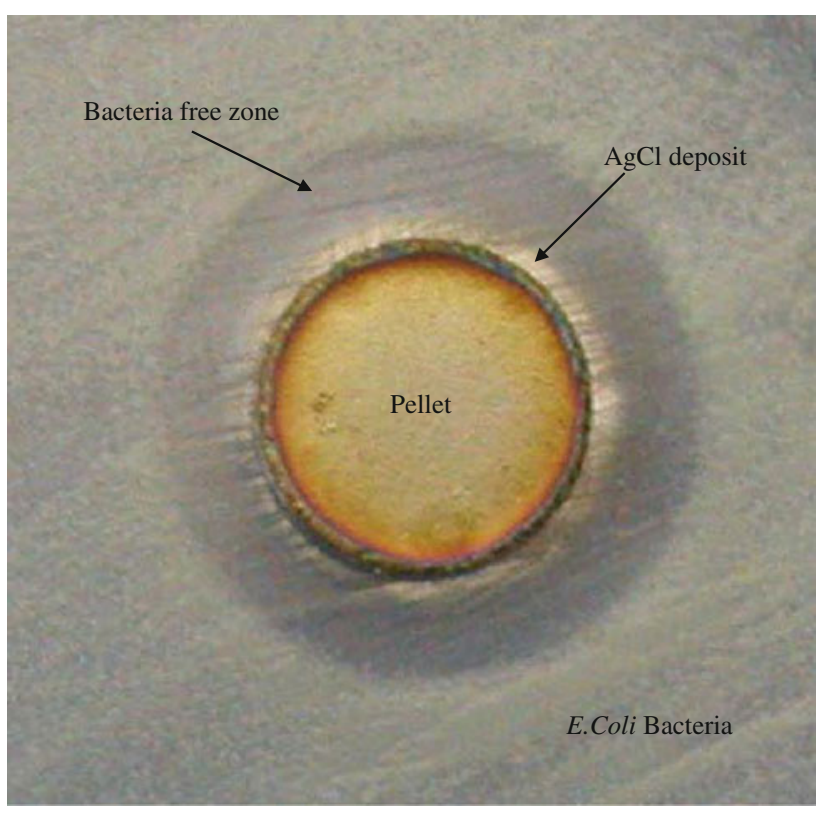

Fig. 5 Bacteria free zone formation and local $\mathrm{AgCl}$ deposition around $29 \% \mathrm{Ag} / \mathrm{TiO}_{2}$ made with $\mathrm{HNO}_{3}$ sol-gel route I

In other words, bactericidal activity (i.e. anti-bacterial zone diameter or the optical density measurements) could be falsified by the presence of chloride ion present in the $\mathrm{MH}$ agar medium through the formation of $\mathrm{AgCl}$. Because chloride ions in $\mathrm{MH}$ medium react with diffusing silver cations to form $\mathrm{AgCl}$; hence, resulting in local deposition of $\mathrm{AgCl}$ in the $\mathrm{MH}$ agar medium or resulting in the optical density in the solution used in minimum inhibition test analyses. That's why we did not use minimum inhibition concentration determination due to adverse effect of chloride in the solution. It was easy to observe the local precipitation of $\mathrm{AgCl}$ in the vicinity of the pellets (especially for $29 \% \mathrm{Ag}$ loading) using reflective optical microscope equipped with a digital camera as seen in Fig. 5. We believe slivery and shiny band close to the perimeter of the pellet is $\mathrm{AgCl}$ deposits. The transparent region after $\mathrm{AgCl}$ deposit is the bacteria free zone, i.e. no bacteria growth. In this bacteria free zone, there may be some $\mathrm{AgCl}$ deposit too but it cannot be seen using optical microscope due to magnification limitation of the optical instrument. Therefore, one could explain the local deposition of $\mathrm{AgCl}$ by the following chemical reaction occurring between $\mathrm{Ag}^{+}$and $\mathrm{Cl}^{-}$ions in the $\mathrm{MH}$ agar medium and also inside the pellets:

$\mathrm{Ag}_{(\mathrm{aq})}^{+}+\mathrm{Cl}_{(\mathrm{aq})}^{-} \leftrightarrow \mathrm{AgCl}_{(\mathrm{aq})}$

XRD analyses of unused (i.e. fresh) xerogels showed that the xerogel made with $\mathrm{HCl}$ sol-gel route II contained both $\mathrm{Ag}$ and $\mathrm{AgCl}$ nano-crystallites and the xerogel made with $\mathrm{HNO}_{3}$ sol-gel route I contained only Ag nano-crystallites, whereas $\mathrm{AgCl}$ was the only crystalline phase present in the 
Table 3 Average crystallite sizes of $29 \% \mathrm{Ag}-\mathrm{TiO}_{2}$ pellets after used in antibacterial tests

\begin{tabular}{lll}
\hline & $\mathrm{Ag}(\mathrm{nm})$ & $\mathrm{AgCl}(\mathrm{nm})$ \\
\hline $29 \% \mathrm{Ag}-\mathrm{AgCl} / \mathrm{TiO}_{2}$ & 15.5 & 25.8 \\
$29 \% \mathrm{Ag} / \mathrm{TiO}_{2}$ & 16.4 & 24.5 \\
\hline
\end{tabular}

xerogel made with additional $\mathrm{HCl}$ treatment sol-gel route III. It seems that $\mathrm{Ag}$ crystallites in the pellets made with the sol-gel routes I and II dissolved more readily by the presence of $\mathrm{Cl}$ anions in the $\mathrm{MH}$ agar medium as compared to the xerogel made with the sol-gel route III because the $\mathrm{Cl}$ anions present in the test medium forces the reaction Eq. 1 to the right. Therefore, the high bactericidal activities are observed with the xerogels containing both $\mathrm{Ag}$ and $\mathrm{AgCl}$ but the release rate of silver from the xerogel containing only $\mathrm{AgCl}$ crystallites is low because the $\mathrm{Cl}$ anions present in the test medium forces the reaction Eq. 1 to the right; hence resulting in low silver ion concentration and the lowest antibacterial zone formation.

When we examined all the xerogels using XRD after the anti-bacterial tests, we found that $\mathrm{AgCl}$ was also formed inside the $29 \% \mathrm{Ag} / \mathrm{TiO}_{2}$ xerogel made with sol-gel route I (it should be noted that in the unused sample, only metallic silver was present). After the antibacterial test, the average crystallite size of $\mathrm{AgCl}$ in the xerogels made with the solgel routes II and I increased to $\sim 26$ and $\sim 25 \mathrm{~nm}$, respectively, as seen in Table 3. These seem to prove our hypothesis that $\mathrm{Cl}$ anions present in the $\mathrm{MH}$ agar medium reacts with Ag crystallites inside the xerogel pellets and also Ag cations diffusing in the MH agar medium. In other words, $\mathrm{AgCl}$ formed inside the pellet and also deposited around the pellet in the $\mathrm{MH}$ agar medium; causing the low antibacterial zone diameter formation. This is also in parallel with our viable cell counting measurements. The amount required for the xerogel made with sol-gel route I was the lowest among the xerogels because of high silver dissolution. The extent of the chloride ion effect depends on chloride ion concentration in both $\mathrm{MH}$ agar medium and the synthesis steps of the sol-gel method used in this study.

\subsection{The effect of repetitive usage of xerogels on the antibacterial activities}

It seems that xerogel containing $\mathrm{Ag}$ is promising antibacterial material since the xerogel containing only $\mathrm{Ag}$ metal (i.e. xerogel made with $\mathrm{HNO}_{3}$ sol-gel route I) result in the highest antibacterial zone diameter and the lowest minimum amount of the xerogel to inhibit the bacteria growth as compared to other xerogels containing $\mathrm{Ag}$ and $\mathrm{AgCl}$. But this is not enough to choose the suitable material for

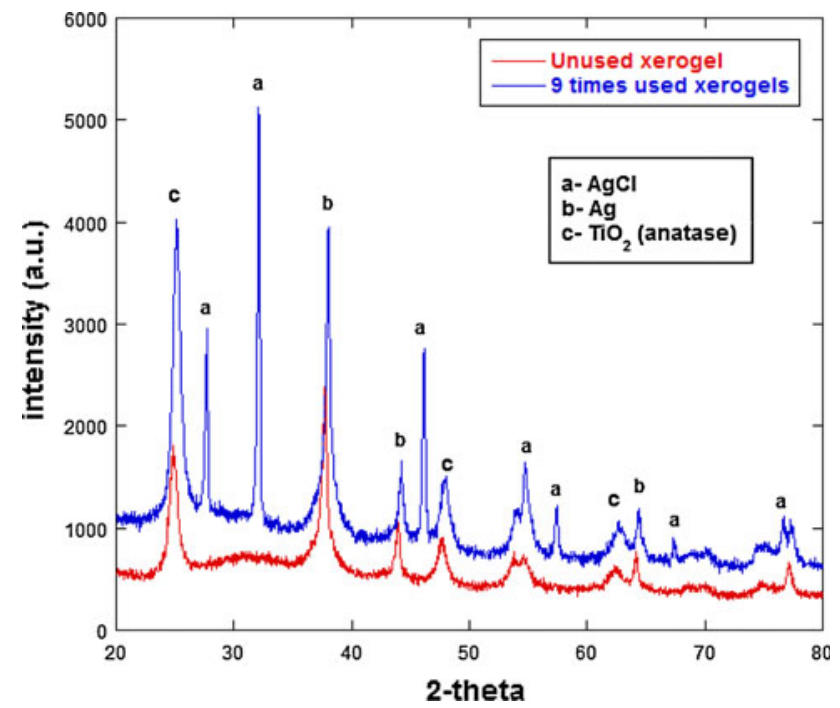

Fig. 6 XRD patterns of $29 \% \mathrm{Ag} / \mathrm{TiO}_{2}$ made with $\mathrm{HNO}_{3}$ sol-gel route I before and after using 9 times in antibacterial tests

antibacterial applications because repetitive usage is also important factor. Therefore, one may expect to observe that the antibacterial zone diameter of the xerogels would decrease continuously because of the loss of silver if they were used repetitively. To check this, we used the same xerogel pellets for 9 times but each test was done with a fresh $\mathrm{MH}$ agar medium streaked with the same concentration of E. coli bacteria (McFarland no. 0.5). Then, the bactericidal activities of the pellets were measured each day. After each measurement, for the next test, another fresh MH agar media were again streaked with $E$. coli and then used pellets that was recovered from the previous tests were directly placed on this fresh growth medium. We found that the zone diameter around $29 \% \mathrm{Ag} / \mathrm{TiO}_{2}$ made with additional $\mathrm{HCl}$ treatment sol-gel route III did not change with the number of usage. However, the zone diameter around $29 \% \mathrm{Ag} / \mathrm{TiO}_{2}$ made with $\mathrm{HCl}$ sol-gel route II and $29 \% \mathrm{Ag} / \mathrm{TiO}_{2}$ made with $\mathrm{HNO}_{3}$ sol-gel route I significantly dropped with the number of usage (data not shown). After 6 usages (i.e. 6 days), $29 \% \mathrm{Ag} / \mathrm{TiO}_{2}$ made with $\mathrm{HCl}$ sol-gel route II and $\mathrm{HNO}_{3}$ sol-gel route I had almost the same antibacterial zone diameter as that of $29 \% \mathrm{Ag} / \mathrm{TiO}_{2}$ made additional $\mathrm{HCl}$ treatment sol-gel route III and stayed the same for the additional 3 days (total of 9 days of test). From the XRD analyses of the xerogels used for 9 times, we found that $\mathrm{AgCl}$ crystallite phase was present in the pellets, as seen in Fig. 6. Thus, this seems to show that a controlled release of $\mathrm{Ag}$ could be achieved when $\mathrm{Ag}$ is in the form of $\mathrm{AgCl}$ crystallite in $\mathrm{TiO}_{2}$. In fact, it is known that a small amount of silver is enough to kill bacteria or inhibit the bacterial growth at low concentrations, even at ppb levels [27]. 


\section{Conclusions}

We show that the controlled release of $\mathrm{Ag}$ from $\mathrm{TiO}_{2}$ could be achieved if $\mathrm{AgCl}$ crystallites were formed inside $\mathrm{TiO}_{2}$. In this study, $\mathrm{AgCl}$ crystallite was successfully formed in $\mathrm{TiO}_{2}$ using the modified sol-gel method and additional $\mathrm{HCl}$ treatment and also the adverse effect of chloride ion was shown. Our findings are:

- The antibacterial zone diameter around Ag containing $\mathrm{TiO}_{2}$ xerogels increases with the silver amount.

- Unnecessary release of silver occurs if silver is not in the form of $\mathrm{AgCl}$ crystallite phase.

- Most importantly, our results showed that without considering chloride ion present in the $\mathrm{MH}$ agar medium, the usage of antibacterial zone diameter and optical density measurements to assess real bactericidal performance of the materials could not be correct due to the possibility of the local precipitation of $\mathrm{AgCl}$ inside the pellet and also in the $\mathrm{MH}$ agar medium through the interaction between diffusing silver and chloride ion.

- $\mathrm{AgCl} / \mathrm{TiO}_{2}$ xerogels made with the additional $\mathrm{HCl}$ treatment sol-gel route III are good candidate for polymers to make long lasting sterilization of materials used in public facilities and for a direct usage in biofilters.

Acknowledgments We would like to thank to Dr. Özlem Çağlar Duvarc1 for her helps on some of the antibacterial tests and for the technical help on bacterial tests, to Dr. Oğuz Bayraktar of chemical engineering department and to Mert Sudagidan of Biotechnology and Bioengineering Central Research Laboratories, Izmir Institute of Technology and also for ICP analyses, to Environmental Research Center, Izmir Institute of Technology.

\section{References}

1. Lin YE, Vidic RD, Stout JE, Yu VL (2002) Appl Environ Microbiol 68(6):2711-2715
2. Galean B, Korff E, Nicholson WL (2003) Appl Environ Microbiol 69(7):4329-4331

3. Silver S (2003) FEMS Microbiol Rev 27:341-353

4. Klasen HJ (2000) Burns 26:117-130

5. Klasen HJ (2000) Burns 26:131-138

6. Simpson K (2003) Plast Addit Compounding 5(5):32-35

7. Vermeiren L, Devlieghere F, Debevere J (2002) Food Addit Contam 19:163-171

8. Gupta A, Maynes M, Silver S (1998) Appl Environ Microbiol 64:5042-5045

9. Sondi I, Sondi SB (2004) J Colloid Interface Sci 275:177-182

10. Sawai J, Kojima H, Igarashi H, Hashimoto A, Shoji S, Sawaki T, Hakoda A, Kawada E, Kokugan T, Shimizu M (2000) World J Microbio Biotechnol 16:187-194

11. Yeo SY, Lee HJ, Jeong SH (2003) J Mater Sci 38:2143-2147

12. Rivera-Garza M, Olguin MT, Garcia-Sosa I, Alcantara D, Rodriguez-Fuentes G (2000) Microporous Mesoporous Mater 39: 431-444

13. Kampf G, Dietze B, Grobe-siestrup C, Wendt C, Martiny H (1998) Antimic Agents Chemother 42(9):2440-2442

14. Kim JW, Lee JE, Kim SJ, Lee JS, Ryu JH, Kim J, Han SH, Chang IS, Suh KD (2004) Polymer 45:4741-4747

15. Estevano LRM, Mendonca-Hagler LCS, Nascimento RSV (2003) Ind End Chem Res 42:5950-5953

16. Jeon HJ, Yi SC, Oh SG (2003) Biomaterials 24:4921-4928

17. Trapalis CC, Kokkoris M, Perdikakis G, Kordas G (2003) J SolGel Sci Technol 26:1213-1222

18. Thiel J, Pakstis L, Buzby S, Raffi M, Ni C, Pochan DJ, Shah SI (2007) Small 3(5):799-803

19. Martinez NN, Castanon GAM, Pina AA, Gutierrez FM, Mondoza JRM, Ruiz F (2008) Nanotechnology 19:6-10

20. Liu Y, Wang X, Yang F, Yang X (2008) Microporous Mesoporous Mater 114:431-439

21. Zhang H, Chen G (2009) Environ Sci Technol 43(8):2905-2910

22. Amin SA, Pazouki M, Hosseinnia A (2009) Powder Technol 196:241-245

23. Campbell K, Na BK, Ko EI (1992) Chem Mater 4(6):1329-1333

24. Li L, Zhu YJJ (2006) Colloid Interface Sci 33:415-418

25. Akhavan O, Ghaderi E (2009) Current Appl Phys 9:1381-1385

26. Balamurugana A, Balossierb G, Laurent-Maquinc D, Pinaa S, Rebeloa AHS, Faureb J, Ferreiraa JMF (2008) Dental Materials 24:1343-1351

27. Kawashita M, Toda S, Kim H, Kokubo T, Masuda N (2003) J Biomed Mater Res Part A 66:266-274 